\title{
Remarks on the Hormonal Background of the Male Equivalent of Polycystic Ovary Syndrome
}

\section{Luboslav Stárka, Michaela Dušková}

Institute of Endocrinology, Prague, Czech Republic

Received November 18, 2020; Accepted April 30, 2021.

Key words: Polycystic ovarian syndrome - Premature androgenic alopecia Androgens - SHBG - Insulin resistance

\begin{abstract}
The hypothesis that the most common female endocrine disease, the polycystic ovarian syndrome (PCOS), has a male equivalent, has recently become more widely accepted. The male form of PCOS is marked by alterations in the secretion of gonadotropins, increased insulin resistance, and changes of the levels of several steroid hormones, with clinical manifestations including premature androgenic alopecia (AGA). Because these symptoms are not always found in men with genetic predispositions, knowledge of the male equivalent of PCOS needs to be supplemented by measurements of adrenal 11-oxygenated C19 steroids, particularly 11 -keto-, and $11 \beta$-hydroxy-derivatives of testosterone and dihydrotestosterone, by focusing on the newly-realized role of skin as an endocrine organ, and by confirming any age-related factors in glucose metabolism disorders in such predisposed men.
\end{abstract}

This study was supported by the Ministry of Health of the Czech Republic, RVO (Institute of Endocrinology - EU, 00023761).

Mailing Address: Prof. RNDr. Luboslav Stárka, MD., DSc., Institute of Endocrinology, Národní 8, 11694 Prague 1, Czech Republic; e-mail: Istarka@endo.cz 


\section{Introduction}

Polycystic ovaries are inherited as an autosomal dominant trait (Carey et al., 1993; Govind et al., 1999), so from the genetic point-of-view it seems likely that in families with women suffering from this genetic predisposition for PCOS (polycystic ovarian syndrome), certain symptoms of PCOS may also appear in males. Starting with early hypotheses that male symptoms may include hypertrichosis, insulin resistance, disorders in the secretion of gonadotropins, and premature androgenic alopecia (AGA), more recent results have confirmed the existence of the male equivalent of PCOS, with premature AGA being the most conspicuous symptom (Dušková and Stárka, 2006). Experts on PCOS generally agree (Aversa et al., 2020) that the male equivalent of PCOS is a disease that brings not just dermal and metabolic symptoms and the increasing the risk of "diseases of civilization", but in affected males it could also influence fertility.

\section{PCOS}

Polycystic ovarian syndrome is one of the most common endocrine diseases in women, affecting about 6-15\% of the female population in developed countries. Azziz et al. (2004) stated that $82 \%$ of female hyperandrogenemia is a result of PCOS. The syndrome has been long recognized, though under various names such as sclerotic ovarian degeneration (1845), a cystic form of chronic oophoritis (1895), and from 1935 as Stein-Leventhal syndrome (Stein and Leventhal, 1935) after the discoverers of the hormonal nature of the disease. In the 1970s, the term polycystic ovarian syndrome became more widely used, and 1980 saw the inclusion of glucose metabolism disorders with emphasis on increased insulin resistance to the syndrome spectrum (Burghen et al., 1980). One key marker is a lowered follicle-stimulating hormone (FSH) level compared to luteinizing hormone (LH), so a defect in the hypothalamic-pituitary axis may be hypothesized, but the pathogenesis of PCOS is not yet entirely clear.

Even a precise definition of this disease was long lacking. According to the Rotterdam criteria of the International Gynecological Association, updated in 2012 (Fauser et al., 2012), affected women must fulfil two of three criteria; namely disorders in the menstrual cycle with anovulation, hyperandrogenemia (whether clinically or according to laboratory hormonal results), and polycystic ovaries demonstrated by imaging methods (Dumesic et al., 2015). When considering the male equivalent of PCOS, this definition is clearly inappropriate.

\section{AGA}

Androgenic alopecia is the loss of hair due to shortening the anagen phase of hair cycle, and can be diffuse or general but usually proceeds with hair loss at the socalled "widow's peaks" and at the vertex. Such hair loss affects up to $80 \%$ of men and $50 \%$ of women over the course of their life. Premature androgenic alopecia (AGA) is defined as alopecia that occurs before 30 years of age, or according to 
some authors before 35 years of age, and reaching at least stage III on the HamiltonNorwood scale. It seems that dihydrotestosterone likely plays the most significant role of hormonal factors affecting hair loss. Changes in the hair growth cycle during the onset of AGA have been described in detail, but the actual causes of AGA are still largely unknown (Kaliyadan et al., 2013). It is clear, however, that the onset of AGA is multifactorial, with genetic background playing a key role (Martinez-Jacobo et al., 2018).

\section{Associations of AGA and PCOS in men}

Based on the autosomal genetic transmission of PCOS, and symptoms of PCOS in the men of families where women have been often stricken with PCOS, researchers have proposed the existence of a male equivalent of PCOS. Suggested signs have included excessive body hair loss (Cooper et al., 1968), changes in gonadotropin and testosterone levels (Givens and Andersen, 1975), premature balding (Ferriman and Purdie, 1979; Lunde et al., 1989; Govind et al., 1999), and insulin resistance (Legro, 2000). At first, most studies dealt with just hypotheses, causalities, or data on men from families with an incidence of PCOS in females. According to a recent meta-analysis (Di Guardo et al., 2020), the first study on the hormonal status of premature AGA was from 2005 (Stárka et al., 2005). Some studies of our group were published even earlier (Stárka et al., 2000, 2004, 2005; Dušková et al., 2004). Currently, however, the male equivalent of PCOS has been demonstrated by multiple studies and has generally been accepted (Cannarella et al., 2017, 2018, 2020; Di Guardo et al., 2019, 2020).

It is also important to note that the attribute "premature" regarding AGA as being before 30 or 35 years of age was chosen more-or-less randomly. Not all men with premature AGA can be considered to be carriers of a male equivalent of PCOS (Dušková et al., 2004; Cannarella et al., 2020). And there is no reason not to search for such an equivalent in men with a later onset of hair loss. In light of the higher prevalence of (non-premature) AGA in men than the prevalence of PCOS in women would indicate, it is likely that only some men with AGA indeed suffer from a male equivalent of PCOS. Especially in these men, hormonal changes may give us clues (Dušková et al., 2004).

Additional signs of a male equivalent of PCOS include clinical epidermal markers attributed to hyperandrogenemia like premature AGA, such as acne and increased body-hair, as a result of hormonal changes. Such changes include increased adrenal secretion activity (dehydroepiandrosterone sulfate - DHEAS, 17 $\alpha$-hydroxyprogesterone), low FSH or increased LH/FSH ratio, and increased free testosterone and anti-mullerian hormone. Metabolic abnormalities include insulin resistance, hyperglycemia, hyperinsulinemia, a tendency to be overweight, and lower levels of sex hormone binding globulin (SHBG). At more advanced ages, metabolic disorders often lead to diabetes mellitus type 2 , cardiovascular disease, and more frequent prostate disease (Cannarella et al., 2020). 
While in PCOS women slight hyperandrogenemia is present (indeed by definition) with increased levels of circulating total testosterone (Dumesic et al., 2015), in men with AGA levels of total testosterone have been found to be within reference ranges (Dušková et al., 2004), slightly increased (Sanke et al., 2016) or even slightly lowered (Canarella et al., 2020). And even though levels of total testosterone in men with AGA may differ significantly from controls, there are still within reference ranges. Lowered SHBG likely plays a role, so that even in men with lower total testosterone the free fraction is still normal. Lowered SHBG levels were already documented in the first hormonal studies on the male equivalent of PCOS (Stárka et al., 2000) and confirmed in many later studies (Arias-Santiago et al., 2011; Sanke et al., 2016; Cannarella et al., 2017, 2018, 2020). Levels of free testosterone, however, do not by themselves explain the clinically observed hyperandrogenization, so other androgens must be considered, including the already-mentioned adrenal androgens, but also other less-studied markers such as adrenal 11-oxygenated C19-steroids. In fact, these have been found at higher concentrations in women with PCOS (O'Reilly et al., 2017). The question remains, if it could be a specific marker for PCOS. A large study focused only on the relationship between body hair distribution and serum androgens concentrations revealed that 11-oxygenated androgens were not positively associated with greater body hair (Skiba et al., 2020). The principal limitation of this study is only self-reported information of body hair distribution. Personal perception of body hair intensity could influence the results.

Both women with PCOS and men with premature androgenic alopecia have shown increased DHEAS levels (Dušková et al., 2004; Stárka et al., 2004, 2005; Dumesic et al., 2015; Sanke et al., 2016). Significantly higher DHEAS levels were found in $75 \%$ of women fulfilling criteria for PCOS, while both $17 \alpha$-hydroxyprogesterone and DHEAS were higher in about half (21 of 46) of men with premature AGA (Cannerella et al., 2020). These results reflect the higher activity of the zona reticularis in the adrenal cortex, and a slightly increased activity of adrenal steroidogenesis in PCOS patients is an accepted explanation. From this point-ofview, it would be useful to measure a wide spectrum of adrenal androgens in men with AGA or with suspected male-equivalent PCOS, as has been done in women (O'Reilly et al., 2017). It has recently been shown (Storbeck et al., 2013; Turcu et al., 2018) that important roles in adrenal androgen effects are played by the above-mentioned 11-oxygenated C19 steroids. Of these, 11-keto-testosterone, 11-keto-dihydrotestosterone, and 11 $\beta$-hydroxy-testosterone are similar to testosterone itself in concentrations and biological activities. How these 11-oxygenated androgens affect hair loss has not yet been studied. It may be speculated, however, that higher adrenal androgen secretion, as yet only observed only for DHEAS, $17 \alpha$-hydroxy-progesterone, and androstenedione, leads also to higher levels of these highly-effective androgens, and that these adrenal products likely play a role in the yet poorly-studied function of skin as an endocrine organ (Zouboulis, 2009; Slominski et al., 2015). 
As for metabolic disorders, premature AGA has been associated with insulin resistance (Matilainen et al., 2000; Vrbíková et al., 2002; Stárka et al., 2005; González-Gonzáles et al., 2009; Arias-Santiago et al., 2011; Sanke et al., 2016; Cannarella et al., 2017; Di Guardo et al., 2020). This has been proposed as a marker for the male equivalent of PCOS (Matilainen et al., 2000), but in light of its wide population distribution range it is likely not a very useful diagnostic marker. In addition, not all authors have found worsening insulin sensitivity. This is also the reason that some authors have concluded that premature balding under the age of 30 years in brothers of women with PCOS should not be considered a symptom of male-equivalent PCOS (Lenarcik et al., 2011). These ambiguous findings may indeed be due to the higher incidence of AGA compared to the incidence of female PCOS in the population. The prevalence of premature AGA compared to PCOS is not yet clearly known, and we do not yet know what precise role is played by a higher sensitivity to androgens in women than in men, or how many cases of non-premature AGA can be categorized as equivalent. Lowered insulin resistance has in fact been found in some men with premature AGA that had characteristic hormonal changes (Dušková et al., 2004; Cannarella et al., 2020).

Questions regarding metabolic changes and disorders of insulin resistance are even ongoing in women with PCOS, with results complicated by the higher incidence of obesity in these women, introducing problems with interpretation. Only some studies have found insulin sensitivity disorders in slender women with PCOS, and most authors have not confirmed these results (Šimková et al., 2020). This adds even greater complexity to the search for a precise definition of a male equivalent of PCOS. Moreover, while in women with PCOS it is known how alterations of various factors in glucose metabolism change with age, this is not yet the case in males with premature AGA or the male equivalent of PCOS.

\section{Conclusion}

The existence of a male equivalent of PCOS has been supported by a number of recent findings. These include hormonal changes, premature androgenic alopecia, and a tendency for insulin resistance. However, a precise definition and diagnostic criteria still need to be delimited, and this will be just as difficult in men as it has been in women.

\section{References}

Arias-Santiago, S., Gutiérrez-Salmerón, M. T., Buenadía-Eisman, A., Girón-Prieto, M. S., Naranjo-Sintes, R. (2011) Sex hormone-binding globulin and risk of hyperglycemia in patients with androgenetic alopecia. J. Am. Acad. Dermatol. 65(1), 48-53.

Aversa, A., La Vignera, S., Rego, R., Gambineri, A., Nappi, A. E., Calogero, A. E., Ferlin, A. (2020) Fundamental concepts and novel aspects of polycystic ovarian syndrome: expert consensus resolutions. Front. Endocrinol. (Lausanne) 11, 516. 
Azziz, R., Sanchez, L. A., Knochenhauer, E. S., Moran, C., Lazenby, J., Stephens, K. C., Taylor, K., Boots, L. R. (2004) Androgen excess in women: Experience with over 1000 consecutive patients. J. Clin. Endocrinol. Metab. 89(2), 453-462.

Burghen, G. A., Givens, J. R., Kitabchi, A. E. (1980) Correlation of hyperandrogenism with hyperinsulinismus in polycystic ovarian syndrome. J. Clin. Endocrinol. Metab. 50(1), 113-116.

Cannarella, R., La Vignera, S., Condorelli, R. A., Calogero, A. E. (2017) Glycolipid and hormonal profiles in young men with early-onset androgenetic alopecia: a meta-analysis. Sci. Rep. 7(1), 7801.

Cannarella, R., Condorelli, R. A., Mongiò̀, L. M., La Vignera, S., Calogero, A. E. (2018) Does a male polycystic ovarian syndrome equivalent exist? J. Endocrinol. Invest. 41(1), 49-57.

Cannarella, R., Condorelli, R. A., Dall'Oglio, F., La Vignera, S., Mongioì, L. M., Micali, G., Calogero, A. E. (2020) Increased DHEAS and decreased total testosterone serum levels in a subset of men with earlyonset androgenetic alopecia: Does a male PCOS-equivalent exist? Int. J. Endocrinol. 2020, 1942126.

Carey, A. H., Chan, K. L., Short, F., White, D., Williamson, R., Franks, S. (1993) Evidence for a single gene effect causing polycystic ovaries and male pattern baldness. Clin. Endocrinol. (Oxf.) 38(6), 653-658.

Cooper, H. E., Spellacy, W. N., Prem, K. H., Cohen, W. D. (1968) Hereditary factors in the Stein-Leventhal syndrome. Am. J. Obstet. Gynecol. 100(3), 371-387.

Di Guardo, F., Cerana, M. C., D'urso, G., Genovese, F., Palumbo, M. (2019) Male PCOS equivalent and nutritional restriction: Are we stepping forward? Med. Hypotheses 126, 1-3.

Di Guardo, F., Ciotta, L., Monteleone, M., Palumbo, M. (2020) Male equivalent of polycystic ovarian syndrome, metabolic and clinical aspects. Int. J. Fertil. Steril. 14(2), 79-83.

Dumesic, D. A., Oberfield, S. E., Stener-Victorin, E., Marshall, J. C., Laven, J. S., Legro, R. S. (2015) Scientific statement on diagnostic criteria, epidemiology and molecular genetics of polycystic ovarian syndrome. Endocr. Rev. 36(5), 487-525.

Dušková, M., Stárka, L. (2006) The existence of male equivalent of polycystic ovary syndrome - The present state of issue. Prague Med. Rep. 107(1), 17-25.

Dušková, M., Čermáková, I., Hill, M., Vaňková, M., Šámalíková, P., Stárka, L. (2004) What may be the markers of the male equivalent of polycystic ovary syndrome? Physiol. Res. 53(3), 287-294.

Fauser, B. C., Tarlatzis, B. C., Rebar, R. W., Legro, R. S., Balen, A. H., Lobo, R., Carmina, E., Chang, J., Yildiz, B. O., Laven, J. S., Boivin, J., Petraglia, F., Wijeyeratne, C. N., Norman, R. J., Dunaif, A., Franks, S., Wild, R. A., Dumesic, D., Barnhart, K. (2012) Consensus on women's health aspects of polycystic ovary syndrome (PCOS): The Amsterdam ESHRE/ASRM-Sponsored $3^{\text {rd }}$ PCOS Consensus Workshop Group. Fertil. Steril. 97(1), 28-38.e25.

Ferriman, D., Purdie, A. W. (1979) The inheritance of polycystic ovarian disease and a possible relationship to premature balding. Clin. Endocrinol. (Oxf.) 11(3), 291-300.

Givens, J. R., Andersen, R. N. (1975) Letter: Serum testosterone in the polycystic ovary syndrome. Am. J. Obstet. Gynecol. 121(8), 1124-1125.

González-González, J. G., Mancillas-Adame, L. G., Fernández-Reyes, M., Gómez-Flores, M., Lavalle-González, F. J., Ocampo-Candiani, J., Villarreal-Pérez, J. Z. (2009) Androgenetic alopecia and insulin resistance in young men. Clin. Endocrinol. (Oxf.) 71(4), 494-499.

Govind, A., Obhrai, M. S., Clayton, R. N. (1999) Polycystic ovaries are inherited as an autosomal dominant trait: Analysis of 29 polycystic ovary syndrome and 10 control families. J. Clin. Endocrinol. Metab. 84(1), 38-43.

Kaliyadan, F., Nambiar, A., Vijayaraghavan, S. (2013) Androgenetic alopecia: an update. Indian J. Dermatol. Venereol. Leprol. 79, 613-625.

Legro, R. S. (2000) Is there a male phenotype in polycystic ovary syndrome families? J. Pediatr. Endocrinol. Metab. 13, 1307-1309 (Suppl. 5). 
Lenarcik, A., Bidzińska-Speichert, B., Tworowska-Bardzińska, U., Krępuła, K. (2011) Hormonal abnormalities in first-degree relatives of women with polycystic ovary syndrome (PCOS). Endokrynol. Pol. 62(2), 129-133.

Lunde, O., Magnus, P., Sandvik, L., Høglo, S. (1989) Familial clustering in the polycystic ovarian syndrome. Gynecol. Obstet. Invest. 28(1), 23-30.

Martinez-Jacobo, L., Villarreal-Villarreal, C. D., Ortiz-López, R., Ocampo-Cadiani, J., Rojas-Martínez, A. (2018) Genetic and molecular aspects of androgenetic alopecia. Indian J. Dermatol. Venereol. Leprol. 84(3), 263-268.

Matilainen, V., Koskela, P., Keinanen-Kiukaanniemi, S. (2000) Early androgenetic alopecia as a marker of insulin resistance. Lancet 356(9236), 1165-1166.

O’Reilly, M. W., Kkempegowda, P., Jenkinson, C., Taylor, A. E., Quanson, J. L., Storbeck, K. H., Arlt, W. (2017) 11-oxygenated C19 steroids are the predominant androgens in polycystic ovary syndrome. J. Clin. Endocrinol. Metab. 102(3), 840-848.

Sanke, S., Chander, R., Jain, A., Garg, T., Yadav, P. (2016) A comparison of the hormonal profile of early androgenetic alopecia in men with the phenotypic equivalent of polycystic ovarian syndrome in women. JAMA Dermatol. 152(9), 986-991.

Šimková, M., Vítků, J., Kolátorová, L., Vrbíková, J., Vosátková, M., Včelák, J., Dušková, M. (2020) Endocrine disruptors, obesity and cytokines - How relevant are they to PCOS? Physiol. Res. 69, S279-S293 (Suppl. 2).

Skiba, M. A., Bell, R. J., Islam, R. M., Karim, M. N., Davis, S. R. (2020) Distribution of body hair in young Australian women and associations with serum androgen concentrations. J. Clin. Endocrinol. Metab. 105(4), dgaa063.

Slominski, A., Manna, P. R., Tuckey, R. C. (2015) On the role of skin in the regulation of local and systemic steroidogenic activities. Steroids 103, 72-88.

Stárka, L., Hill, M., Poláček, V. (2000) Hormonal profile in men with premature androgenic alopecia. Sb. Lek. 101(1), 17-22. (in Czech)

Stárka, L., Čermáková, I., Dušková, M., Hill, M., Doležal, M., Poláček, V. (2004) Hormonal profile of men with premature balding. Exp. Clin. Endocrinol. Diabetes 112(1), 24-28.

Stárka, L., Dušková, M., Čermáková, I., Vrbíková, J., Hill, M. (2005) Premature androgenic alopecia and insulin resistance. Male equivalent of polycystic ovary syndrome? Endocr. Regul. 39, 127-131.

Stein, I. F., Leventhal, M. L. (1935) Amenorhea associated with bilateral polycystic ovaries. Am. J. Obstet. Gynecol. 29, 181-186.

Storbeck, K. H., Bloem, L. M., Africander, D., Schloms, L., Swart, P., Swart, A. C. (2013) 11 $\beta$-hydroxydihydrotestosterone and 11-ketodihydrotestosterone, novel C19 steroids with androgenic activity: A putative role in castration resistant prostate cancer? Mol. Cell. Endocrinol. 377(1-2), 135-146.

Turcu, A. F., Nanba, A. T., Auchus, R. J. (2018) The rise, fall, and resurrection of 11-oxygenated androgens in human physiology and disease. Horm. Res. Paediatr. 89(5), 284-291.

Vrbíková, J., Bendlová, B., Hill, M., Vaňková, M., Vondra, K., Stárka, L. (2002) Insulin sensitivity and ß-cell function in women with polycystic ovary syndrome. Diabetes Care 25(7), 1217-1222.

Zouboulis, C. C. (2009) The skin as an endocrine organ. Dermatoendocrinol. 1(5), 250-252. 